\title{
Characterization of the transcriptome and EST-SSR development in Boea clarkeana, a desiccation-tolerant plant endemic to China
}

\author{
Ying Wang ${ }^{1,2}$, Kun Liu ${ }^{1,2}$, De Bi ${ }^{1}$, Shoubiao Zhou ${ }^{\text {Corresp., }}{ }^{1,3}$, Jianwen Shao ${ }^{\text {Corresp. }{ }^{1,2}}$ \\ ${ }^{1}$ College of Life Sciences, Anhui Normal University, Wuhu, Anhui, China \\ 2 Anhui Provincial Key Laboratory of the Conservation and Exploitation of Biological Resources, Anhui Normal University, Wuhu, Anhui, China \\ ${ }^{3}$ College of Environmental Science and Engineering, Anhui Normal University, Wuhu, Anhui, China \\ Corresponding Authors: Shoubiao Zhou, Jianwen Shao \\ Email address: zhoushoubiao@vip.163.com, 545491044@qq.com
}

Background. Desiccation-tolerant (DT) plants can recover full metabolic competence upon rehydration after losing most of their cellular water (>95\%) for extended periods of time. Functional genomic approaches such as transcriptome sequencing can help us understand how DT plants survive and respond to dehydration, which has great significance for plant biology and improving the drought tolerance of crops. Boea clarkeana Hemsl. (Gesneriaceae) is a DT dicot yledonous herb. Its genomic sequences characteristics remain unknown. Based on transcriptomic analyses, polymorphic EST-SSR (simple sequence repeats in expressed sequence tags) molecular primers can be designed, which will greatly facilitate further investigations of the population genetics and demographic histories of DT plants. Methods. In the present study, we used the platform Illumina HiSeq ${ }^{\mathrm{TM}} 2000$ and de novo assembly technology to obtain leaf transcriptomes of $B$. clarkeana and conducted a BLASTX alignment of the sequencing data and protein databases for sequence classification and annotation. Then, based on the sequence information, the EST-SSR markers were developed, and the functional annotation of ESTs containing polymorphic SSRs were obtained through BLASTX. Results. A total of 91,449 unigenes were generated from the leaf cDNA library of $B$. clarkeana. Based on a sequence similarity search with a known protein database, 72,087 unigenes were annotated. Among the annotated unigenes, a total of 71,170 unigenes showed significant similarity to the known proteins of 463 popular model species in the Nr database, and 59,962 unigenes and 32,336 unigenes were assigned to GO classifications and Cluster of Orthologous Groups (COG), respectively. In addition, 44,924 unigenes were mapped in 128 KEGG pathways. Furthermore, a total of 7,610 unigenes with 8,563 microsatellites were found. Seventy-four primer pairs were selected from 436 primer pairs designed for polymorphism validation. SSRs with higher polymorphism rates were concentrated on dinucleotides, 
pentanucleotides and hexanucleotides. Finally, 17 pairs with stable, highly polymorphic loci were selected for polymorphism screening. There was a total of 65 alleles, with 2-6 alleles at each locus. Primarily due to the unique biological characteristics of plants, the $H_{\mathrm{E}}$ $(0-0.196), H_{0}(0.082-0.14)$ and PIC $(0-0.155)$ per locus were very low. The functional annotation distribution centered on ESTs containing di- and tri-nucleotide SSRs, and the ESTs containing primers $\mathrm{BC} 2, \mathrm{BC} 4$ and $\mathrm{BC} 12$ were annotated to vegetative dehydration/desiccation pathways. Discussion. This work is the first genetic study of $B$. clarkeana as a new plant resource of DT genes. A substantial number of transcriptome sequences were generated in this study. These sequences are valuable resources for gene annotation and discovery as well as molecular marker development. These sequences could also provide a valuable basis for future molecular studies of $B$. clarkeana. 
1 Characterization of the transcriptome and EST-SSR development in Boea clarkeana, a

2 desiccation-tolerant plant endemic to China

3

4 Ying Wang ${ }^{1,3}$, Kun Liu' ${ }^{1,3}$, De Bi ${ }^{1}$, Shoubiao Zhou ${ }^{1,2}$, Jianwen Shao ${ }^{1,3}$

$6 \quad{ }^{1}$ College of Life Sciences, Anhui Normal University, Wuhu, Anhui, China

$7 \quad{ }^{2}$ College of Environmental Science and Engineering, Anhui Normal University, Wuhu, Anhui,

8 China

$9{ }^{3}$ Anhui Provincial Key Laboratory of the Conservation and Exploitation of Biological

10 Resources, Wuhu, Anhui, China

12 Corresponding author:

13 Shoubiao Zhou

14 Email address: zhoushoubiao@vip.163.com;

15 Jianwen Shao

16 Email address: 545491044@qq.com. 


\section{Abstract}

Background. Desiccation-tolerant (DT) plants can recover full metabolic competence upon rehydration after losing most of their cellular water ( $>95 \%)$ for extended periods of time.

Functional genomic approaches such as transcriptome sequencing can help us understand how DT plants survive and respond to dehydration, which has great significance for plant biology and improving the drought tolerance of crops. Boea clarkeana Hemsl. (Gesneriaceae) is a DT dicotyledonous herb. Its genomic sequences characteristics remain unknown. Based on transcriptomic analyses, polymorphic EST-SSR (simple sequence repeats in expressed sequence tags) molecular primers can be designed, which will greatly facilitate further investigations of the population genetics and demographic histories of DT plants.

Methods. In the present study, we used the platform Illumina HiSeq ${ }^{\mathrm{TM}} 2000$ and de novo assembly technology to obtain leaf transcriptomes of B. clarkeana and conducted a BLASTX alignment of the sequencing data and protein databases for sequence classification and annotation. Then, based on the sequence information, the EST-SSR markers were developed, and the functional annotation of ESTs containing polymorphic SSRs were obtained through BLASTX.

Results. A total of 91,449 unigenes were generated from the leaf cDNA library of B. clarkeana.

Based on a sequence similarity search with a known protein database, 72,087 unigenes were annotated. Among the annotated unigenes, a total of 71,170 unigenes showed significant similarity to the known proteins of 463 popular model species in the $\mathrm{Nr}$ database, and 59,962 unigenes and 32,336 unigenes were assigned to GO classifications and Cluster of Orthologous 
38 Groups (COG), respectively. In addition, 44,924 unigenes were mapped in 128 KEGG pathways.

39 Furthermore, a total of 7,610 unigenes with 8,563 microsatellites were found. Seventy-four

40 primer pairs were selected from 436 primer pairs designed for polymorphism validation. SSRs

41 with higher polymorphism rates were concentrated on dinucleotides, pentanucleotides and

42 hexanucleotides. Finally, 17 pairs with stable, highly polymorphic loci were selected for

43 polymorphism screening. There was a total of 65 alleles, with 2-6 alleles at each locus. Primarily

44 due to the unique biological characteristics of plants, the $H_{\mathrm{E}}(0-0.196), H_{\mathrm{O}}(0.082-0.14)$ and PIC

$45(0-0.155)$ per locus were very low. The functional annotation distribution centered on ESTs

46 containing di- and tri-nucleotide SSRs, and the ESTs containing primers BC2, BC4 and BC12

47 were annotated to vegetative dehydration/desiccation pathways.

48 Discussion. This work is the first genetic study of $B$. clarkeana as a new plant resource of DT genes. A substantial number of transcriptome sequences were generated in this study. These sequences are valuable resources for gene annotation and discovery as well as molecular marker

51 development. These sequences could also provide a valuable basis for future molecular studies of 52
B. clarkeana. 
Introduction

55

56

57

Resurrection plants are desiccation-tolerant (DT), which enables them to recover full metabolic competence upon rehydration after losing most of their cellular water $(>95 \%)$ for extended periods of time (Farrant, Brandt \& Lindsey, 2007). Though non-vascular plants and spores of tracheophytes are commonly DT (Rodriguez et al., 2010), this feature is rare in angiosperms (Gaff, 1971; Porembski \& Barthlott, 2000; Proctor \& Pence, 2002). The mechanisms of DT are different between the extant lower orders and angiosperms (Farrant, Brandt \& Lindsey, 2007). Understanding how DT plants survive and respond to dehydration has great significance for plant biology and crop drought tolerance improvement, which could contribute to future water resource management decisions. Moreover, research on DT angiosperms could inform crop cultivation (Farrant, Brandt \& Lindsey, 2007; Oliver et al., 2011a; Gechev et al., 2012; Xiao et al., 2015). In recent decades, research has focused on revealing the physiological and molecular mechanisms of DT in angiosperm plants and their recovery processes (Bianchi et al., 1993; Bernacchia, Salamini \& Bartels, 1996; Sherwin \& Farrant, 1998; Cooper \& Farrant, 2002; Collett et al., 2003, 2004; Schneider et al., 2003; Alcazar et al., 2011; Oliver et al., 2011a, 2011b; Christ et al., 2014; Zhu et al., 2015). While a functional genomic approach, such as transcriptome sequencing, could be fruitful for exploring the mechanisms of DT (Xiao et al., 2015), transcriptomics could identify the metabolic processes involved in DT. GO (Gene Ontology, http://www.blast2go.com/b2ghome) and COG (Cluster of Orthologous Groups, http://www.ncbi.nlm.nih.gov/COG/) analyses can also help us understand the distribution of functional genes in plants at the macro level (Conesa et al., 2005; Ye et al., 2006). Moreover, the 
75

gene products of metabolic processes and the functions of genes related to cellular processes can be detected by BLASTX using the KEGG database (Kyoto Encyclopedia of Genes and Genomes, http://www.kegg.jp/) (Kanehisa et al., 2008). These approaches can help us study gene behaviors in biologically complex processes, such as vegetative dehydration/desiccation pathways, in DT plants (Xiao et al., 2015). However, to the best of our knowledge, only a few gene expression and EST sequencing studies have been performed in angiosperms with DT, including the dicot species Craterostigma plantagineum (Bockel, Salamini \& Bartels, 1998), Boea hygrometrica (Xiao et al., 2015), and Haberlea rhodopensis (Rodriguez et al., 2010; Gechev et al., 2013) and the monocot species Sporobolus stapfianus (Neale et al., 2000; Le et al., 2007), Xerophyta viscosa (Mundree et al., 2000; Mowla et al., 2002; Lehner et al., 2008), and Xerophyta humilis (Collett et al., 2004; Illing et al., 2005; Mulako et al., 2008).

Boea (Gesneriaceae) is a rare group of resurrection plants within angiosperms (Liu, Hu \& Zhao, 2007; Xiao et al., 2015). Boea clarkeana Hemsl. is a desiccation-tolerant herb endemic to China. The whole plant, detached leaf and leaf segment all retain the DT phenotype, and the excellent drought tolerance of this plant has been of concern in the last few years (Chao et al., 2013; Zhang et al., 2016). B. clarkeana is a small perennial dicotyledonous plant that is mainly distributed in 8 provinces and 1 municipality along the middle-lower reaches of the Yangtze River in China (Li, 1996; Li \& Wang, 2005). It is found only on rock outcrops (such as inselbergs) among some lithophytes, where dehydration occurs frequently (Jenks \& Wood, 2007). It is commonly used as a medicinal plant to treat traumatic hemorrhage and traumatic injury ( $\mathrm{Li}$ \& Wang, 2005). However, genomic sequences of B. clarkeana are scarce, and only a few 
nucleotide sequences are found in public databases (http://www.ncbi.nlm.nih.gov/). To fill this critical gap and obtain the first genomic resources, we used the Illumina HiSeq ${ }^{\mathrm{TM}} 2000$ platform and de novo assembly to obtain leaf transcriptomes of $B$. clarkeana and conducted a BLASTX (http://blast.ncbi.nlm.nih.gov/Blast.cgi) alignment of the sequencing data and protein databases for sequence classification and annotation.

We also assessed the SSRs, or microsatellites, that are distributed universally in gene coding and non-coding regions. As the major tool of genetic research, the neutral SSR markers are widely used in botanic sciences and functional SSR markers might affect gene function by influencing recombination and chromatin organization, regulating gene expression and activity, etc.(Cavagnaro et al., 2010; Li et al., 2012a; Zalapa et al., 2012). In DT plants, identifying functional genes that contain functional SSRs could help us to understand the evolution and expression of these genes, making SSRs a valuable resource for genetic studies (Li et al., 2002; Gupta et al., 2003). Therefore, based on the B. clarkeana transcriptome, 17 pairs of polymorphic EST-SSR molecular primers were developed and characterized. The results of this study will greatly facilitate further investigations of the genetics and demographic histories of populations of this DT plant.

\section{Materials and Methods}

\section{Plant materials and genomic DNA extraction}

5 The materials of 11 natural populations were sampled from 6 provinces and 1 municipality in China that covered the vast majority of the natural habitats of B. clarkeana (Li \& Wang, 2005). 
117 Young leaves were collected, rapidly dried and preserved in silica gel.DNA extraction was

118 carried out using the QIAGEN ${ }^{\circledR}$ DNeasy ${ }^{\circledR}$ Plant Mini Kit (QIAGEN, Germany).

119

120

\section{$R N A$ isolation and $c D N A$ library construction}

121 The young leaves of three individual B. clarkeana plants from the population of Mt. Fenghuang in Anhui Province $\left(30^{\circ} 88^{\prime} \mathrm{N}, 118^{\circ} 02^{\prime} \mathrm{E}\right)$ were collected, mixed and frozen in liquid nitrogen; then, the sampled tissues were stored at $-80^{\circ} \mathrm{C}$ until RNA extraction. Total RNA was isolated using a TRIzolKit (Life Technologies, USA) and DNase I (TaKaRa, Japan) followed the manufacturer's protocols. After total RNA was obtained, mRNA + poly(A) were isolated using beads with Oligo (dT), and fragmentation buffer was added to cut the mRNA into short

fragments. Then, first-strand cDNA was obtained from the RNA sequence fragments using

reverse transcriptase and random primers (Invitrogen, Carlsbad, CA), and second-strand cDNA adapters, a single 'A' base was added to the 3' end of these cDNA fragments to facilitate end repair. Based on the amplification of these products, the cDNAs were separated on an agarose gel, and the cDNA library was generated.

\section{Sequencing and de novo assembly}

The raw reads were produced from the cDNA library using an Illumina HiSeq ${ }^{\mathrm{TM}} 2000$ genomic sequencer at the Beijing Genomics Institute (BGI, Shenzhen, China, 
138 by filtering the raw reads. We used the filter_fq program (BGI, Shenzhen, China) to remove

139 reads with more than 5\% unknown nucleotides $(\mathrm{N})$ and low-quality sequences with more than $20 \%$

140 low-quality bases (quality value $\leq 10$ ) and adaptors to obtain clean reads. Then, we used the short

141 read assembly program Trinity (Release-2013-02-25, http://trinityrnaseq.sourceforge.net/) for de

142 novo transcriptome assembly by combining the clean reads into contigs with a sequence

143 fragment length of $200 \mathrm{bp}( \pm 25 \mathrm{bp}$ ) (Grabherr et al., 2011). Two contigs were then connected into

144 a single scaffold, and we called the resulting sequences unigenes. These unigenes were removed to prevent redundancy with TGICL (version 2.1) and further spliced to generate non-redundant unigenes that were as long as possible (Pertea et al., 2003). The raw sequencing data with accession number SRX1600046 were deposited in the Sequence Read Archive (SRA) of

National Center for Biotechnology Information (NCBI), which will be released upon publication.

\section{Functional annotation and classification of unigenes}

BLASTX alignment $\left(E\right.$-value $\left.<10^{-5}\right)$ between the unigenes and protein databases, such as NCBI non-redundant protein $(\mathrm{Nr}), \mathrm{GO}, \mathrm{COG}$, and $\mathrm{KEGG}$, was performed to annotate and classify the transcriptome. Based on the $\mathrm{Nr}$ database annotation, we used Blast2GO v2.5.0 to obtain GO terms with an $E$-value threshold of $10^{-5}$ (Conesa et al., 2005). With the Web Gene Ontology Annotation Plot (WEGO) (Ye et al., 2006), the distributions of GO terms were plotted to describe the categories, and the unigenes were aligned to the COG database for possible functional prediction and classification. The unigenes containing SSRs were also aligned to euKaryotic Orthologous Groups (KOGs) via BLASTX. Finally, we mapped the unigenes to each 
159 160

161

level 3 pathway graph using the KEGG database to obtain pathway annotations for the unigenes.

\section{EST-SSR mining, primer design and polymorphism identification}

SSRs from unigenes were detected and located using MIcroSAtellite (MISA, http://pgrc.ipkgatersleben.de/misa/misa.html) (Zalapa et al., 2012). Compound SSRs (two or more SSRs in which the interval was no more than $100 \mathrm{bp}$ ) were excluded, and only SSRs with flanking sequences longer than $150 \mathrm{bp}$ and containing 2 to 6 repeat motifs were considered. The mono-, di-, tri-, tetra-, penta- and hexa-nucleotide motif SSRs with a minimum of 12, 6, 5, 5, 4 and 4 repeats, respectively, were detected. We designed primer pairs using the online program Primer3.0 (http://www.onlinedown.net/soft/51549.htm) with the following criteria: (1) a product sequences length of 100-300 bp and no secondary structure; (2) a primer length of 18-28 bp with an optimum length of $23 \mathrm{bp}$; (3) a Tm of $55-65^{\circ} \mathrm{C}$ with an optimum $\mathrm{Tm}$ of $60^{\circ} \mathrm{C}$ and a difference between the Tm values of the forward and reverse primers of no greater than $4^{\circ} \mathrm{C}$; and (4) a guanine-cytosine (GC) content of $40-60 \%$, with $50 \%$ as the optimum. For other parameters, the default settings were used.

Seventy-four primer pairs divided into two groups were selected for DNA amplification. The first group of 50 primer pairs was randomly selected for amplification, and the motifs that had more polymorphic alleles in the first group were used to increase the selected ratio in the second 24 primer pairs. The mixed DNA from 3 individuals from different populations of $B$. clarkeana was used to verify the amplification products, and the primers that amplified successfully were chosen for primary polymorphism identification. Using these primers, 
180

181

182

amplification was conducted using 12 individuals from 11 natural populations. Then, the DNA of 128 individuals from 11 populations were amplified using primer pairs that had more polymorphic loci for further identification of polymorphisms. The ESTs containing SSRs were aligned to GO, COG, and KEGG databases through BLASTX to help us understand the functional annotations of the sequences.

Using fluorescently-labeled (6-FAM, HEX, TAMRA or ROX) M13-tailed (5'-

TGTAAAACGACGGCCAGT-3') primers to accurately screen the variation among individuals. PCR was performed in a $15-\mu \mathrm{L}$ reaction containing $2.5 \mathrm{mM} \mathrm{MgCl}_{2}$ and dNTP (TaKaRa, Dalian, China), $0.5 \mathrm{U}$ of Taq polymerase (TaKaRa, Dalian, China), $1 \times$ PCR buffer, and $50 \mathrm{ng}$ of genomic DNA. The primers included $0.04 \mu \mathrm{M}$ forward primers, $0.01 \mu \mathrm{M}$ M13-tailed reverse primers, and $0.04 \mu \mathrm{M}$ M13 primers with fluorescent tails. The annealing temperature was different for each locus. We used $54^{\circ} \mathrm{C}$ as the unified annealing temperature for PCR, and the amplification conditions were as follows: initial denaturation at $94^{\circ} \mathrm{C}$ for $5 \mathrm{~min} ; 35$ cycles of $30 \mathrm{~s}$ at $94^{\circ} \mathrm{C}, 40 \mathrm{~s}$ annealing at $54^{\circ} \mathrm{C}$, and $45 \mathrm{~s}$ elongation at $72^{\circ} \mathrm{C}$; and a final extension at $72^{\circ} \mathrm{C}$ for 10 min. After screening on a 1.0\% agarose gel, the sequence typing of successfully amplified products was performed using an ABI 3730 DNA Analyzer (Applied Biosystems, Foster City, California, USA). Then, we manually scored alleles using GeneMarker software (version 2.2.0). Deviations from Hardy-Weinberg equilibrium (HWE) were calculated using the online tool GENEPOP (http://www.genepop.curtin.edu.au/) with Bonferroni's correction. The number of alleles $\left(N_{\mathrm{A}}\right)$ was calculated using MicroChecker (version 2.2.3). The expected $\left(H_{\mathrm{E}}\right)$ and observed heterozygosity $\left(H_{\mathrm{O}}\right)$ of each locus were detected by GenALEx 6 (Peakall \&Smouse, 
201

202

203

204

205

206

207

208

209

210

211

212

213

214

215

216

217

218

219

220

221

2006), and the polymorphism information content (PIC) was calculated using the PowerMarker program (version 3.25) (Liu \& Muse, 2005). Then, neutral markers were detected using LOSITAN (Beaumont \& Nichols, 1996; Antao et al., 2008).

\section{Results}

\section{Illumina sequencing and de novo assembly}

Sequencing success was determined by the length of the reads, as longer reads would increase the probability of SSRs being discovered (Zalapa et al., 2012). A total of 9,361,934,460 nt bases were generated in this study. After cleaning and quality checks, we obtained 104,021,494 clean reads with Q20 bases (sequences with sequencing error rates $<1 \%$ ) at $97.55 \%$, and the $\mathrm{N}$ (ambiguous bases) and GC contents were 0 and $45.43 \%$, respectively. De novo assembly was performed using the Trinity program; a total of 94,546 contigs were generated with an average length of $487 \mathrm{nt}$ and an N50 value of 1,075 nt. Finally, a total of 91,449 unigenes with a total length of $148,176,175 \mathrm{nt}$ were detected, and the average length and N50 were 1,620 nt and 2,389 nt, respectively. The final assembled transcripts of $B$. clarkeana were longer than those of its sibling species, i.e., the Primulina species and B. hygrometrica, which were assembled using Illumina (Ai et al., 2015) and the 454 pyrosequencing platform (Zhu et al., 2015), respectively. As 454 pyrosequencing produces longer reads than Illumina, the sequencing results were ideal in this study (Zalapa et al., 2012). A summary of the sequence assembly after Illumina sequencing is shown in Table 1. The sequence-length distribution of the unigenes is shown in Figure 1. 


\section{Functional annotation and classification of unigenes}

223 For function annotation analysis, we obtained 71,170, 59,962, 32,336 and 44,929 unigenes

224 annotated to the $\mathrm{Nr}, \mathrm{GO}, \mathrm{COG}$ and KEGG databases, respectively. In total, 72,078 unigenes

225 (78.82\% of all assembled unigenes) were successfully annotated in the present study. This

number of successful annotations was more than those reported for other DT plants, including $B$.

hygrometrica (66.6\% (Zhu et al., 2015) and 47.09\% (Xiao et al. 2015)) and Syntrichia caninervis

(58.7\%) (Gao et al., 2014), which indicates that the functions of genes in B. clarkeana are better conserved in this study.

\section{Nr annotation}

In total, 71,170 unigenes were annotated from 463 popular model species in the $\mathrm{Nr}$ databases.

The species distribution of $\mathrm{Nr}$ annotations (Figure 2) mainly comprised Lycopersicon esculentum

234 (35.1\%), Vitis vinifera (27.8\%), Amygdalus persica (6.7\%), castor bean (Ricinus communis;

6.1\%), black cottonwood (Populus trichocarpa; 5.2\%), Fragaria vesca subsp. vesca (3.2\%) and

Glycine $\max (2.8 \%)$. The most common species found in terms of this similarity were those of

Solanaceae, with which 6 species had similar genes $(26,585,37.35 \%)$. Only a small fraction of

all transcripts showed similarities to genes in other species. The structural features of the proteincoding genes were similar to those of their homologs in other previously studied DT plants, including C. plantagineum (Rodriguez et al., 2010), B. hygrometrica (Zhu et al., 2015) and $H$. rhodopensis (Gechev et al., 2013). The species distribution of $\mathrm{Nr}$ annotations primarily consisted of $V$. vinifera, $R$. communis and $P$. trichocarpa, which showed significant homology; however, $B$. 
243

244

245

246

247

248

249

250

251

252

253

254

255

256

257

258

259

260

261

262

263

clarkeana showed some differences in our study, which indicated that B. clarkeana shares a common origin with $L$. esculentum and $V$. vinifera.

\section{GO and KEGG classification}

Based on the $\mathrm{Nr}$ annotations, 59,962 unigenes (65.57\% of all unigenes) were assigned to three ontologies and subdivided into 55 functional GO terms. The annotation scale in B. clarkeana was much greater than that in the related species B. hygrometrica (28.71\% (Xiao et al., 2015); and 43.7\% (Zhu et al., 2015)). Similarly to previous studies, the 'Biological process' $(49.45 \%)$ was the main ontology, followed by 'Cellular component' and 'Molecular function' ontologies (37.11\% and $13.43 \%$ ). A high percentage of genes were classified under the GO terms 'Cellular process', 'Metabolic process', 'Cell', 'Cell part', 'Organelle', 'Catalytic activity' and 'Binding' (Gupta et al., 2003; Durand et al., 2010; Blanca et al., 2011; Li et al., 2012a; Xiao et al., 2015; Zhu et al., 2015). The assignment of GO terms in B. clarkeana in this study focused on 'Single-organism process', 'Physiological response to stimulus', 'Biological regulation', 'Localization', 'Macromolecular complex', 'Symplast' and 'Transporter activity', which reflected the functional gene expression characteristics of $B$. clarkeana during normal growth. Compared with the related species B. hygrometrica under different DT treatments, there were more functional GO terms, more dispersed gene distributions, and different sets of GO terms, especially in the 'Molecular function' ontology (Figure 3) (Xiao et al., 2015; Zhu et al., 2015). This result was mainly due to selective gene expression caused by the adaptation of cells to various physiological states and environmental changes. 
system; 'Glycerophospholipid metabolism' $(803,1.79 \%)$ in vesicular trafficking for protein

receptor interactions; 'Plant hormone signal transduction' $(1,783,3.97 \%)$ for abiotic stress

responses; the mRNA surveillance $(1,027,2.29 \%)$ pathway for damaged transcript removal; and

'Photosynthesis' $(154,0.34 \%)$ and 'Nitrogen metabolism' $(154,0.34 \%)$ for the depletion of

transcripts during dehydration. In addition, some other environment-related pathways, including

'Phosphatidylinositol signaling system' (535, 1.19\%), ‘ABC transporters' $(499,1.11 \%)$ and

'Circadian rhythm-plant' $(377,0.84 \%)$ were also enriched. These results indicate that in normal

metabolic processes, $B$. clarkeana maintains its abundant vegetative dehydration/desiccation

pathways. The results of our study are consistent with those of other studies, which identified the

plant genes and gene products with central roles in DT (Gechev et al., 2012; Xiao et al., 2015).

\section{COG and KOG classification of unigenes with SSRs}

In total, 56,493 functionally annotated unigenes from 32,336 (35.36\% of all unigenes) COG 
unigenes were assigned to 25 possible functional categories in COG annotations (Figure 4).

'Transcription' $(5,322,13.46 \%)$. The smallest groups were 'Cell motility’ $(228,0.71 \%)$,

'Extracellular structures' (17, 0.05\%) and 'Nuclear structure' (14, 0.04\%). This pattern is similar

for some angiosperms, including Camelina sativa (Liang et al., 2013), Apium graveolens (Fu,

Wang \& Shen, 2013) and Chrysanthemum nankingense (Wang et al., 2013). The 'Replication,

recombination and repair' $(17.20 \%)$ category has abundant genes in B. clarkeana, and this plant showed more repaired genes.

After SSR detection using the MIcroSAtellite (MISA) software with unigenes as references, 7,610 unigenes carrying 8,563 SSRs were found. Then, 3,267 unigenes with SSRs had hits in 24 categories of the KOG database without 'Nuclear structure'. Among 24 categories, the largest group was 'General function prediction' $(1,166,35.69 \%$ of unigenes with SSRs in KOG), followed by 'Transcription' (797, 24.40\%), 'Replication, recombination and repair' (737, $22.56 \%)$ and 'Signal transduction mechanisms' $(684,20.94 \%)$. Compared with other studies of

EST-SSRs (Li et al., 2012a; Liang et al., 2013; Liu et al., 2013). 'Replication, recombination and repair' and 'Signal transduction mechanisms' (684, 20.94\%) were highlighted in B. clarkeana.

These 3,267 ESTs will provide a valuable repository of abundant information for future functional SSR studies. 
306

307

308

309

310

311

312

313

314

315

316

317

318

319

320

321

322

323

324

325

326

All 91,449 assembled unigenes were used to mine potential SSRs in this study, and a total of 7,610 unigenes containing 8,563 SSRs were identified. Other reports have identified approximately 2000 EST-SSRs using NGS (Next-Generation Sequencing) (Liu et al., 2013;

Wang et al., 2013; Xiang et al., 2015); the quantity of EST-SSRs in our study was significantly larger, which was probably due to the use of longer reads and the expression characteristics of the species (Zalapa et al., 2012).

Among those unigenes containing SSRs, 338 SSRs presented a compound formation, and 812 unigenes contained more than one SSR. On average, one SSR was found every $17.30 \mathrm{~kb}$. Among the identified SSRs, dinucleotide motifs were the most abundant $(3,991,46.61 \%$ of all SSRs), followed by mono- $(2,163,25.26 \%)$, tri- $(1,957,22.85 \%)$, hexa- $(267,3.12 \%)$, tetra- (198, $2.3 \%)$, and penta- $(36,0.42 \%)$ nucleotide motifs. This result was similar to the findings reported for A. graveolens (Fu, Wang \& Shen, 2013) and Hevea brasiliensis (Li et al., 2012a). The distributions and frequencies of different motifs are shown in Figure 5.

Among all SSR loci, 109 different motifs were identified. The largest subset of mononucleotides were A/T $(2,093,24.44 \%$ of all SSRs $)$, and there were only $70 \mathrm{C} / \mathrm{G}$ nucleotides in total. Of the dinucleotides, AT/AT $(1,564,18.26 \%)$ and AG/CT $(1,391,16.24 \%)$ were roughly equivalent, followed by AC/GT $(1,035,12.09 \%)$. Of the trinucleotides, AAG/CTT $(441,5.15 \%)$ was the most common, followed by AAT/ATT $(389,4.54 \%)$ and AGC/GCT $(341,3.98 \%)$. The ACAT/ATGT $(18,0.21 \%)$ motif comprised the most common tetranucleotide, and the most common pentanucleotides and hexanucleotides were AAAAG/CTTTT (42, 0.49\%) and AAGAGC/GCTCTT $(68,0.79 \%)$, respectively. The repeat numbers of most SSRs ranged from 4 
327

328

330

331

332

333

334

335

336

337

338

339

340

341

342

343

344

345

346

347

to 12 , and the most frequent repeat number was $6(2,066,24.13 \%)$, followed by $5(1,233,14.40 \%)$ and $7(1,113,13.00 \%)$. Furthermore, the length of SSRs ranged from 12 to 25 bp (Figure 6). Among the di- and trinucleotides, the most common lengths were $12 \mathrm{bp}$ and $15 \mathrm{bp}$, respectively. The longest di-, tri- or tetranucleotide was $24 \mathrm{bp}$, whereas the longest pentanucleotide was $25 \mathrm{bp}$ in length; all hexanucleotides were $24 \mathrm{bp}$.

\section{Development and validation of polymorphic SSR markers}

As a result, a total of 436 (only $5.73 \%$ of SSR-containing ESTs) eligible primer pairs (mononucleotide, 1; di-, 191; tri-, 205; tetra-, 5; penta-, 12; hexa-, 22) were designed. Primers could not be successfully designed for the other 7,174 sequences, primarily due to their overly long sequence lengths and insufficient flank lengths as well as the abundance of sequences containing mononucleotides. Then, 74 primer pairs (dinucleotide, 20; tri-, 38; penta-, 3; hexa-, 13) were selected to validate the amplification across a composite sample of 3 individuals. A total of 60 primer pairs (81.08\% of 74 primer pairs) showed stable and clear amplification.

Meanwhile, the 14 remaining pairs with failed PCR produced multiple bands or showed unstable amplification. After polymorphism screening across 12 individuals, twenty-three primer pairs were found to be monomorphic and 37 were found to be polymorphic. Among 37 polymorphic primer pairs, 17 pairs of highly polymorphic and stable loci across 128 individuals from 11 populations, which covered the majority of habitats of these plants, were selected for further polymorphism screening. For the 17 polymorphic loci, there were 2-6 alleles at each locus, with a total of 65 alleles. The $H_{\mathrm{E}}, H_{\mathrm{O}}$ and PIC per locus ranged from 0 to $0.196,0$ to 0.14 and 0.155 to 
348

349

350

351

352

0.664 , respectively. For the PIC values of the 17 polymorphic loci, 8 pairs had highly informative scores ( $\mathrm{PIC}>0.50)$ and 5 pairs had weakly informative scores $(0<\mathrm{PIC}<0.25)$ (Table 2).

\section{Functional annotation of SSR-containing ESTS}

The functional annotation distribution of SSR-containing ESTs centered on ESTs containing diand tri-nucleotide SSRs (BC1-BC10). With the exception of one EST (BC12), the ESTs containing penta- and hexa- nucleotide SSRs (BC11 to BC17) had almost no functional annotations. However, the $\mathrm{ESTs}$ containing $\mathrm{BC} 2, \mathrm{BC} 4$ and $\mathrm{BC} 12$ were annotated by the $\mathrm{KEGG}$ analysis to vegetative dehydration/desiccation pathways (Table 3 and Table S1). Thus, these ESTs may contain the SSRs involved in regulating the function of DT-related genes. Although the SSR variation of the functional markers did not agree with the neutral theory, the neutrality test conducted using LOSITAN showed that all 17 primer pairs agreed with the neutral theory (Figure 7). These 17 primer pairs may have contained exactly neutral markers, or perhaps the sample size and randomness of sampling in this study was deficient. Therefore, increasing the sample size in future studies will provide us with more accurate results. It should be noted that compared with previous reports that identified EST-SSRs using NGS, the hexa- nucleotide SSRcontaining ESTs, which comprised a relatively larger number of sequences with more polymorphic markers and fewer annotations, were unique to B. clarkeana (Liu et al., 2013;

Wang et al., 2013; Xiang et al., 2015). 
369

370

371

372

373

374

375

376

377

378

379

380

381

382

383

384

385

386

387

\section{Discussion}

\section{Gene expression characteristics and comparison of $\mathrm{B}$. clarkeana with $\mathrm{B}$. hygrometrica}

This work is the first genetic study of B. clarkeana as a new plant resource of DT genes. Notably, a large amount of EST data were available, enabling a better understanding of gene expression in this species. B. clarkeana was compared with the related species B. hygrometrica, and both plants showed KEGG enrichment of vegetative dehydration/desiccation pathways; these results showed the common characteristics of metabolic pathways in DT plants. However, there were some differences between the transcriptome data of these two species. First, the GC content $(45.43 \%)$ of $B$. clarkeana was higher than that of $B$. hygrometrica, which was close to the distribution centered value of coding sequences (Matassi et al., 1989). Likely due to the lack of dehydration stress, the annotated unigene percentage ( $78.82 \%$ of all assembled unigenes) and the enrichment of GO (65.57\% of all unigenes) and KEGG (49.12\%) annotations in this study were much greater than those of B. hygrometrica (Nr, 47.09\%; GO, 28.71\%; KEGG, 24.43\% (Xiao et al., 2015) and Nr, 66.6\%; GO, 43.7\%; KEGG, 15.1\% (Zhu et al., 2015)). Second, due to different sequencing depths or selective gene expression at various physiological stages, the structural features of gene expression in B. hygrometrica was quite different under various environmental pressures. Zhu et al. (2015) found that B. hygrometrica matched in the Nr database with $V$. vinifera, $R$. communis and P. trichocarpa, whereas Xiao et al. (2015) found shared genes in the genomes of B. hygrometrica, Solanum tuberosum and Solanum lycopersicum (Solanales). Thus,

Solanales and $V$. vinifera could both contain the main components of the protein-coding genes of $B$. hygrometrica, which would be similar to the structural features of gene expression in $B$. 
390

391

392

393

394

clarkeana in the present study.

\section{EST-SSR characteristics of $\mathrm{B}$. clarkeana}

A significant number of SSRs were identified in the present study. A higher number of SSRs indicated stronger environmental adaptation capabilities (Zalapa et al., 2012); therefore, $B$. clarkeana should be highly adaptable to different environments due to the large number of SSRs contained in its ESTs. Moreover, the 'Transcription', 'Replication, recombination and repair' and 'Signal transduction mechanisms' reflect the strong ability of B. clarkeana to undergo environmental adaptation.

Intrinsic features (such as repeat number, motif size, and length) could influence the rate and probability of slippage. These features were the strongest predictors of microsatellite mutability (Kelkar et al., 2008). The increased probability of slippage and mutation rates may be due to, for example, a greater number of repeats (Ellegren, 2004; Kelkar et al., 2008), a greater length irrespective of the repeat numbers (Webster, Smith \& Ellegren, 2002), and lengths that were inversely proportional to their motif sizes (Chakraborty et al., 1997). Additionally, the mutation rates might vary among SSRs with different motif compositions due to the dissimilarities of secondary DNA structures (Baldi \& Baisnee, 2000). In this study, 37 pairs (dinucleotide, 13; tri-, 13; penta-, 2; hexa-, 9) of 74 primer pairs (dinucleotide, 20; tri-, 38; penta-,

3 ; hexa-, 13) that were selected to validate the amplification results were polymorphic. The percentage of polymorphism was $65 \%$ in dinucleotides (13 of the 20 selected were polymorphic),

$34.21 \%$ (13 of 38 ) in trinucleotides, $66.67 \%$ ( 2 of 3 ) in pentanucleotides and $69.23 \%$ (9 of 13$)$ in 
411 hexanucleotides. As a result, in our study, SSRs with higher polymorphism rates were

412 concentrated on shorter motifs with a higher number of repeats (dinucleotides, 65\%) and longer

413 motifs with fewer repeats (hexanucleotides, 69.23\%; pentanucleotides, 66.67\%). Our analysis

414 confirmed that mutability might increase with both increased repeat number and greater length,

415 as reported by Baldi \& Baisnee (2000).

416 Compared with other SSR and EST-SSR reports (Choudhary et al., 2009; Li et al., 2012a,

417 2012b; Yuan et al., 2012; Fu, Wang \& Shen, 2013), the observed number of polymorphic

418 primers was actually higher, but the polymorphism level of the markers and the $H_{\mathrm{O}}, H_{\mathrm{E}}, \mathrm{HWE}$

419 and PIC values of the B. clarkeana population were still much lower in our study and were

420 similar to those of B. hygrometrica (Xiao et al., 2015). These results could be attributed to two

421 main reasons: first, the number of SSRs and polymorphisms of the DNA protein-coding

sequence was expected to be lower than that in non-coding sequences, and the mutation rate

within these regions was lower than that in other DNA sequences (Blanca et al., 2011; Zalapa et

al., 2012). Second, B. clarkeana is a plant with a short stature that requires scattered light. As

this plant grows on the north side of rock outcrops (mostly limestone) and in the shadow of trees

and shrubs (Chao et al., 2013), the long-distance dispersal potential of windborne seeds might be

significantly reduced. Furthermore, the occurrence of biparental inbreeding could be universal in

plants with high self-compatibility (Li \& Wang, 2005), which would cause lower genetic

variability within populations of $B$. clarkeana.

430 
432 In this study, 91,449 unigenes were detected by NGS transcriptomics. A total of 8,563 SSRs

433 were identified from 7,610 unigenes, 72,087 unigenes were successfully annotated to protein

434 databases, and polymorphic primer pairs of EST-SSRs were also developed. These results

435 indicated that transcriptome sequencing is a highly efficient method of EST-SSR identification in

436 non-model species that lack a reference genome and associations with functional genes.

437 Therefore, by characterizing phenotypic features, these species can be identified (Li et al., 2002).

438 These data will accelerate our identification of functional genes and genetic variation in DT

439 plants, including $B$. clarkeana. In addition, polymorphic primer pairs can continue to be

440 developed from the remaining primers of EST-SSRs. The large-scale transcriptome dataset is a

441 powerful resource for functional gene marker-assisted selection and DT exploration in Boea

442 plants.

443

\section{Acknowledgments}

445 We are grateful to Cunhai Li and Fei Tan (Guanshan National Nature Reserve, JiangXi, China)

446 for their assistance with the sampling. 
448

449

450

451

452

453

454

455

456

457

458

459

460

461

462

463

464

465

466

467

468

\section{References}

Ai B, Gao Y, Zhang XL, Tao JJ, Kang M, Huang HW. 2015. Comparative transcriptome resources of eleven Primulina species, a group of 'stone plants' from a biodiversity hot spot. Molecular Ecology Resources 15: 619-632. DOI: 10.1111/1755-0998.12333.

Alcazar R, Bitrian M, Bartels D, Koncz C, Altabella T, Tiburcio AF. 2011. Polyamine metabolic canalization in response to drought stress in Arabidopsis and the resurrection plant Craterostigma plantagineum. Plant Signaling \& Behavior 6(2): 243-250. DOI: 10.4161/psb.6.2.14317.

Antao T, Lopes A, Lopes RJ, Beja-Pereira A, Luikart G. 2008. LOSITAN: a workbench to detect molecular adaptation based on a Fst-outlier method. BMC Bioinformatics 9: 323. DOI: $10.1186 / 1471-2105-9-323$.

Baldi P, Baisnee PF. 2000. Sequence analysis by additive scales: DNA structure for sequences and repeats of all lengths. Bioinformatics 16: 865-889. DOI: 10.1093/bioinformatics/16.10.865.

Beaumont MA, Nichols RA. 1996. Evaluating loci for use in the genetic analysis of population structure. Proceedings of the Royal Society of London Series B, Biological Sciences 263: 1619-1626. DOI: 10.1098/rspb.1996.0237.

Bernacchia G, Salamini F, Bartels D. 1996. Molecular characterization of the rehydration process in the resurrection plant Craterostigma plantagineum. Plant Physiology 111(4): 1043-1050. DOI: 10.1104/pp.111.4.1043.

Bianchi G, Gamba A, Limiroli R, Pozzi N, Elster R, Salamini F, Bartels D. 1993. The 
unusual sugar composition in leaves of the resurrection plant Myrothamnus flabellifolia. Physiologia Plantarum 87: 223-226. DOI: 10.1111/j.1399-3054.1993.tb00146.x.

Blanca J, Cañizares J, Roig C, Ziarsolo P, Nuez F, Picó B. 2011. Transcriptome characterization and high throughput SSRs and SNPs discovery in Cucurbita pepo (Cucurbitaceae). BMC Genomics 12(3): 1-15. DOI: 10.1186/1471-2164-12-104.

Bockel C, Salamini F, Bartels D. 1998. Isolation and characterization of genes expressed during early events of the dehydration process in the resurrection plant Craterostigma plantagineum. Journal of Plant Physiology 152: 158-166. DOI: 10.1016/S01761617(98)80127-2.

Cavagnaro PF, Senalik DA, Yang L, Simon PW, Harkins TT, Kodira CD, Huang S, Weng Y. 2010. Genome-wide characterization of simple sequence repeats in cucumber (Cucumis sativus L.). BMC Genomics 11(1): 1-18. DOI: 10.1186/1471-2164-11-569.

Chakraborty R, Kimmel M, Stivers DN, Davison LJ, Deka R. 1997. Relative mutation rates at di-, tri-, and tetranucleotide microsatellite loci. Proceedings of the National Academy of Sciences of the United States of America 94: 1041-1046.

Chao TC, Zhou SB, Chang LL, Chen YS, Xu HJ, Zhou QK. 2013. Effects of light intensity on the leaf morphology and physiological parameters of Boea clarkeana. Chinese Journal of Ecology 32: 1161-1167.

Choudhary S, Sethy NK, Shokeen B, Bhatia S. 2009. Development of chickpea EST-SSR markers and analysis of allelic variation across related species. Theoretical and Applied Genetics 118(3): 591-608. DOI: 10.1007/s00122-008-0923-z. 
490

491

492

493

494

495

496

497

498

499

\section{Christ B, Egert A, Suessenbacher I, Kraeutler B, Bartels D, Peters S, Hoertensteiner S.}

2014. Water deficit induces chlorophyll degradation via the 'PAO/phyllobilin'pathway in leaves of homoio-(Craterostigma pumilum) and poikilochlorophyllous (Xerophyta viscosa) resurrection plants. Plant, Cell \& Environment 37(11): 2521-2531. DOI: $10.1111 /$ pce. 12308 .

Clarke K, Gorley R. 2001. PRIMER v5: user manual/tutorial. Plymouth: Primer-E Ltd.

Collett H, Butowt R, Smith J, Farrant J, Illing N. 2003. Photosynthetic genes are differentially transcribed during the dehydration-rehydration cycle in the resurrection plant, Xerophyta humilis. Journal of Experimental Botany 54(392): 2593-2595. DOI: $10.1093 / \mathrm{jxb} / \mathrm{erg} 285$.

Collett H, Shen A, Gardner M, Farrant JM, Denby KJ, Illing N. 2004. Towards transcript profiling of desiccation tolerance in Xerophyta humilis: construction of a normalized $11 \mathrm{k}$ $X$. humilis cDNA set and microarray expression analysis of $424 \mathrm{cDNAs}$ in response to dehydration. Physiologia Plantarum 122: 39-53. DOI: 10.1111/j.13993054.2004.00381.x.

Conesa A, Gotz S, Garcia-Gomez JM, Terol J, Talon M, Robles M. 2005. Blast2GO: a universal tool for annotation, visualization and analysis in functional genomics research. Bioinformatics 21(18): 3674-3676. DOI: 10.1093/bioinformatics/bti610.

Cooper K, Farrant JM. 2002. Recovery of the resurrection plant Craterostigma wilmsiifrom desiccation: protection versus repair. Journal of Experimental Botany 53(375): 18051813. DOI: $10.1093 / \mathrm{jxb} / \mathrm{erf028}$. 
511 Durand J, Bodénès C, Chancerel E, Frigerio J-M, Vendramin G, Sebastiani F, Buonamici

512 A, Gailing O, Koelewijn H-P, Villani F. 2010. A fast and cost-effective approach to develop and map EST-SSR markers: oak as a case study. BMC genomics 11(1): 570. DOI: 10.1186/1471-2164-11-5.

515

516

517

518

519

520

521

522

523

524

525

526

527

528

529

530

531

Ellegren H. 2004. Microsatellites: simple sequences with complex evolution. Nature Reviews Genetics 5(6): 435-445. DOI: 10.1038/nrg1348.

Farrant JM, Brandt W, Lindsey GG. 2007. An overview of mechanisms of desiccation tolerance in selected angiosperm resurrection plants. Plant Stress 1: 72-84.

Fu N, Wang Q, Shen H-L. 2013. De novo assembly, gene annotation and marker development using Illumina paired-end transcriptome sequences in celery (Apium graveolens L.). PloS One 8(2): e57686. DOI: 10.1371/journal.pone.0057686.

Gaff DF. 1971. Desiccation-tolerant flowering plants in Southern Africa. Science 174(4013): 1033-1034. DOI: 10.1126/science.174.4013.1033.

Gao B, Zhang D, Li X, Yang H, Wood AJ. 2014. De novo assembly and characterization of the transcriptome in the desiccation-tolerant moss Syntrichia caninervis. BMC Research Notes 7: 490. DOI: 10.1186/1756-0500-7-490.

Gechev TS, Benina M, Obata T, Tohge T, Sujeeth N, Minkov I, Hille J, Temanni MR, Marriott AS, Bergstrom E, Thomas-Oates J, Antonio C, Mueller-Roeber B, Schippers JH, Fernie AR, Toneva V. 2013. Molecular mechanisms of desiccation tolerance in the resurrection glacial relic Haberlea rhodopensis. Cellular and Molecular Life Sciences 70(4): 689-709. DOI: 10.1007/s00018-012-1155-6. 
532 Gechev TS, Dinakar C, Benina M, Toneva V, Bartels D. 2012. Molecular mechanisms of

533 desiccation tolerance in resurrection plants. Cellular and Molecular Life Sciences 69(19):

534 3175-3186. DOI: 10.1007/s00018-012-1088-0.

535

536

537

538

539

540

541

542

543

544

545

546

547

548

549

550

551

552

Grabherr MG, Haas BJ, Yassour M, Levin JZ, Thompson DA, Amit I, Adiconis X, Fan L, Raychowdhury R, Zeng Q. 2011. Full-length transcriptome assembly from RNA-Seq data without a reference genome. Nature Biotechnology 29: 644-652. DOI: 10.1038/nbt.1883.

Gupta PK, Rustgi S, Sharma S, Singh R, Kumar N, Balyan HS. 2003. Transferable EST-SSR markers for the study of polymorphism and genetic diversity in bread wheat. Molecular Genetics \& Genomics 270(4): 315-323. DOI: 10.1007/s00438-003-0921-4.

Illing N, Denby KJ, Collett H, Shen A, Farrant JM. 2005. The signature of seeds in resurrection plants: a molecular and physiological comparison of desiccation tolerance in seeds and vegetative tissues. Integrative \& Comparative Biology 45(5): 771-787. DOI: 10.1093/icb/45.5.771.

Jenks MA, Wood AJ, eds. 2007. Plant desiccation tolerance. Oxford, UK: Blackwell Publishing Ltd.

Kanehisa M, Araki M, Goto S, Hattori M, Hirakawa M, Itoh M, Katayama T, Kawashima S, Okuda S, Tokimatsu T, Yamanishi Y. 2008. KEGG for linking genomes to life and the environment. Nucleic Acids Research 36(Database issue): D480-484. DOI: 10.1093/nar/gkm882.

Kelkar YD, Tyekucheva S, Chiaromonte F, Makova KD. 2008. The genome-wide 
553

554

555

556

557

558

559

560

561

562

563

564

565

566

567

568

569

570

571

572

573

determinants of human and chimpanzee microsatellite evolution. Genome Research 18(1): 30-38. DOI: 10.1101/gr.7113408.

\section{Le TN, Blomstedt CK, Kuang J, Tenlen J, Gaff DF, Hamill JD, Neale AD. 2007.}

Desiccation-tolerance specific gene expression in leaf tissue of the resurrection plant Sporobolus stapfianus. Functional Plant Biology 34: 589-600. DOI: 10.1071/FP06231.

\section{Lehner A, Chopera DR, Peters SW, Keller F, Mundree SG, Thomson JA, Farrant JM.} 2008. Protection mechanisms in the resurrection plant Xerophyta viscosa: cloning, expression, characterisation and role of XvINO1, a gene coding for a myo-inositol 1phosphate synthase. Functional Plant Biology 35: 26-39. DOI: 10.1093/jxb/erm056.

Li DJ, Deng Z, Qin B, Liu XH, Men ZH. 2012a. De novo assembly and characterization of bark transcriptome using Illumina sequencing and development of EST-SSR markers in rubber tree (Hevea brasiliensis Muell. Arg.). BMC Genomics 13: 192. DOI: 10.1186/1471-2164-13-192.

Li M, Zhu L, Zhou CY, Lin L, Fan YJ, Zhuang ZM. 2012b. Development and characterization of EST-SSR markers from Scapharca broughtonii and their transferability in Scapharca subcrenata and Tegillarca granosa. Molecules 17: 1071610723. DOI: 10.3390/molecules170910716.

Li YC, Korol AB, Fahima T, Beiles A, Nevo E. 2002. Microsatellites: genomic distribution, putative functions and mutational mechanisms: a review. Molecular Ecology 11 (12): 2453-2465. DOI: 10.1046/j.1365-294X.2002.01643.x.

Li ZY, Wang YZ. 2005. Plants of Gesneriaceae in China. Henan, China: Henan Science and 
Technology Publishing House.

575

576

577

578

579

580

581

582

583

584

585

586

587

588

589

590

591

592

593

594

Li ZY. 1996. The georaphical distribution of the subfamily Cyrtandroideae Endl. emend. Burtt (Gesneriaceae). Acta Phytotaxonomica Sinica 34: 341-360.

Liang C, Liu X, Yiu SM, Lim BL. 2013. De novo assembly and characterization of Camelina sativa transcriptome by paired-end sequencing. BMC Genomics 14: 146. DOI: 10.1186/1471-2164-14-146.

Liu G, Hu Y, Zhao F. 2007. Molecular cloning of BcWRKY1 transcriptional factor gene from Boea crassifolia Hemsl and its preliminary functional analysis. Acta Scientiarum Naturalium-Universitatis Pekinensis 43:446-452.

Liu K, Muse SV. 2005. PowerMarker: an integrated analysis environment for genetic marker analysis. Bioinformatics 21(9): 2128-2129. DOI: 10.1093/bioinformatics/bti282.

Liu ZP, Chen TL, Ma LC, Zhao ZG, Zhao PX, Nan ZB, Wang YR. 2013. Global transcriptome sequencing using the Illumina platform and the development of EST-SSR markers in Autotetraploid alfalfa. PLoS One 8(12): e83549. DOI: 10.1371/journal.pone.0083549.

Matassi G, Montero LM, Salinas J, Bernardi G. 1989. The isochore organization and the compositional distribution of homologous coding sequences in the nuclear genome of plants. Nucleic Acids Research 17(13): 5273-5290. DOI: 0.1093/nar/17.13.5273.

Mowla SB, Thomson JA, Farrant JM, Mundree SG. 2002. A novel stress-inducible antioxidant enzyme identified from the resurrection plant Xerophyta viscosa Baker. Planta 215(5): 716-726. DOI: 10.1007/s00425-002-0819-0. 
595

596

Mulako I, Farrant JM, Collett H, Illing N. 2008. Expression of Xhdsi-1VOC, a novel member of the vicinal oxygen chelate (VOC) metalloenzyme superfamily, is up-regulated in leaves and roots during desiccation in the resurrection plant Xerophyta humilis (Bak) Dur and Schinz. Journal of Experimental Botany 59: 3885-3901. DOI: 10.1093/jxb/ern226.

Mundree SG, Whittaker A, Thomson JA, Farrant JM. 2000. An aldose reductase homolog from the resurrection plant Xerophyta viscosa Baker. Planta 211(5): 693-700. DOI: $10.1007 / \mathrm{s} 004250000331$.

\section{Neale AD, Blomstedt CK, Bronson P, Le TN, Guthridge K, Evans J, Gaff DF, Hamill JD.} 2000. The isolation of genes from the resurrection grass Sporobolus stapfianus which are induced during severe drought stress. Plant, Cell \& Environment 23: 265-277. DOI: 10.1046/j.1365-3040.2000.00548.x.

Oliver MJ, Guo LN, Alexander DC, Ryals JA, Wone BWM, Cushman JC. 2011a. A sister group contrast using untargeted global metabolomic analysis delineates the biochemical regulation underlying desiccation tolerance in Sporobolus stapfianus. Plant Cell 23: 1231-1248. DOI: $10.1105 /$ tpc. 110.082800.

Oliver MJ, Jain R, Balbuena TS, Agrawal G, Gasulla F, Thelen JJ. 2011b. Proteome analysis of leaves of the desiccation-tolerant grass, Sporobolus stapfianus, in response to dehydration. Phytochemistry 72(10): 1273-1284. DOI: 10.1016/j.phytochem.2010.10.020.

Peakall R, Smouse PE. 2006. GENALEX 6: genetic analysis in Excel. Population genetic software for teaching and research. Moleculary Ecology Notes 6: 288-295. DOI: 10.1111/j.1471-8286.2005.01155.x. 
616

617

618

619

620

621

622

623

624

625

626

627

628

629

630

631

632

633

634

635

636

Pertea G, Huang X, Liang F, Antonescu V, Sultana R, Karamycheva S, Lee Y, White J, Cheung F, Parvizi B, Tsai J, Quackenbush J. 2003. TIGR Gene Indices clustering tools (TGICL): a software system for fast clustering of large EST datasets. Bioinformatics 19(5): 651-652. DOI: 10.1093/bioinformatics/btg034.

Porembski S, Barthlott W. 2000. Granitic and gneissic outcrops (inselbergs) as centers of diversity for desiccation-tolerant vascular plants. Plant Ecology 151: 19-28. DOI: 10.1023/A:1026565817218.

Proctor MCF, Pence VC. 2002. Vegetative tissues: bryophytes, vascular resurrection plants and vegetative propagules. In: Black M, Pritchard HW, eds. Desiccation and survival in plants: drying without dying. New York: CABI Publishing, 207-237.

Rodriguez MC, Edsgard D, Hussain SS, Alquezar D, Rasmussen M, Gilbert T, Nielsen BH, Bartels D, Mundy J. 2010. Transcriptomes of the desiccation-tolerant resurrection plant Craterostigma plantagineum. Plant Journal 63(2): 212-228. DOI: 10.1111/j.1365313X.2010.04243.x.

Schneider H, Manz B, Westhoff M, Mimietz S, Szimtenings M, Neuberger T, Faber C, Krohne G, Haase A, Volke F. 2003. The impact of lipid distribution, composition and mobility on xylem water refilling of the resurrection plant Myrothamnus flabellifolia. New Phytologist 159: 487-505. DOI: 10.1046/j.1469-8137.2003.00814.x.

Sherwin HW, Farrant JM. 1998. Protection mechanisms against excess light in the resurrection plants Craterostigma wilmsii and Xerophyta viscosa. Plant Growth Regulation 24: 203-210. DOI: 10.1023/A:1005801610891. 
637

638

639

640

641

642

643

644

645

646

647

648

649

650

651

652

653

654

655

656

657

Wang HB, Jiang JF, Chen SM, Qi XY, Peng H, Li PR, Song AP, Guan ZY, Fang WM, Liao

Y, Chen FD. 2013. Next-generation sequencing of the Chrysanthemum nankingense

(Asteraceae) transcriptome permits large-scale unigene assembly and SSR marker

discovery. PLoS One 8(4): e62293. DOI: 10.1371/journal.pone.0062293.

Webster MT, Smith NG, Ellegren H. 2002. Microsatellite evolution inferred from humanchimpanzee genomic sequence alignments. Proceedings of the National Academy of Sciences of the United States of America 99(13): 8748-8753. DOI:

10.1073/pnas.122067599.

Xiang XY, Zhang ZX, Wang ZG, Zhang XP, Wu GL. 2015. Transcriptome sequencing and development of EST-SSR markers in Pinus dabeshanensis, an endangered conifer endemic to China. Molecular Breeding 35: 1-10. DOI: 10.1007/s11032-015-0351-0.

Xiao LH, Yang G, Zhang LC, Yang XH, Zhao S, Ji ZZ, Zhou Q, Hu M, Wang Y, Chen M. 2015. The resurrection genome of Boea hygrometrica: a blueprint for survival of dehydration. Proceedings of the National Academy of Sciences of the United States of America 112: 5833-5837. DOI: 10.1073/pnas.1505811112.

Ye J, Fang L, Zheng HK, Zhang Y, Chen J, Zhang ZJ, Wang J, Li ST, Li RQ, Bolund L. 2006. WEGO: a web tool for plotting GO annotations. Nucleic Acids Research 34(Web Server issue): W293-W297. DOI: 10.1093/nar/gk1031.

Yuan N, Sun Y, Nakamura K, Qiu YX. 2012. Development of microsatellite markers in heterostylous Hedyotis chrysotricha (Rubiaceae). American Journal of Botany 99(2): e43-45. DOI: 10.3732/ajb.1100304. 
658 Zalapa JE, Cuevas H, Zhu HY, Steffan S, Senalik D, Zeldin E, McCown B, Harbut R,

659 Simon P. 2012. Using next-generation sequencing approaches to isolate simple sequence

660 repeat (SSR) loci in the plant sciences. American Journal of Botany 99(2): 193-208. DOI:

$661 \quad$ 10.3732/ajb.1100394.

662 Zhang DD, Zhou SB, Zhou H, Liu F, Yang SY, Ma ZH. 2016. Physiological response of Boea

663 clarkeana to dehydration and rehydration. Chinese Journal of Ecology 35: 72-78.

664 Zhu Y, Wang B, Phillips J, Zhang ZN, Du H, Xu T, Huang LC, Zhang XF, Xu GH, Li WL.

665 2015. Global transcriptome analysis reveals acclimation-primed processes involved in the

666 acquisition of desiccation tolerance in Boea hygrometrica. Plant \& Cell Physiology 56:

667 1429-1441. DOI: $10.1093 /$ pcp/pcv059. 
Tables

670 Table 1 Summary of sequence assembly using Illumina sequencing.

\begin{tabular}{lll}
\hline Sequence & Items & Value \\
\hline Reads & Total raw reads & $110,834,050$ \\
& Total clean reads & $104,021,494$ \\
& Total clean nucleotides (nt) & $9,361,934,460$ \\
& Q20 percentage (\%) & 97.55 \\
N percentage (\%) & 0 \\
GC percentage (\%) & 45.43 \\
Total number & 94,546 \\
Total length (nt) & $46,012,409$ \\
Mean length (nt) & 1,075 \\
Contig N50 (nt) & 487 \\
& Total number & 91,449 \\
& Total length (nt) & $148,176,175$ \\
& Mean length (nt) & 1,620 \\
& Unigene N50 (nt) & 2,389 \\
Distinct clusters & 55,888 \\
Distinct singletons & 35,561 \\
\hline
\end{tabular}

671 
673 Table 2 Characteristics of 17 polymorphic EST-SSR markers.

\begin{tabular}{|c|c|c|c|c|c|c|c|c|c|}
\hline Locus & Primer sequence 5'-3, & $\begin{array}{l}\text { Repeat } \\
\text { motif }\end{array}$ & $N_{\mathrm{A}}$ & $\begin{array}{l}\text { Size } \\
\text { range (bp) }\end{array}$ & $\boldsymbol{H}_{\mathrm{E}}$ & $H_{\mathrm{O}}$ & HWE $^{\mathbf{a}}$ & PIC & $\begin{array}{l}\text { GenBank } \\
\text { accession no. }\end{array}$ \\
\hline $\mathrm{BC} 1$ & $\begin{array}{l}\text { F:GCAGTTCTGTGCAGTACCATACAT } \\
\text { R:GGCTTCTGATCAGGTTTCTGAAT }\end{array}$ & $(\mathrm{TA})_{6}$ & 4 & $172-182$ & 0.065 & 0.038 & $0.036^{*}$ & 0.193 & $\operatorname{Pr} 032805680$ \\
\hline $\mathrm{BC} 2$ & $\begin{array}{l}\text { F:GAGATCCCAGATCCAGATCTTCT } \\
\text { R:AACATTAATGGAAACACGTCGTC }\end{array}$ & $(\mathrm{TC})_{6}$ & 3 & $160-164$ & 0.038 & 0.023 & $0.192 \mathrm{n} . \mathrm{s}$ & 0.423 & Pr032805689 \\
\hline $\mathrm{BC} 3$ & $\begin{array}{l}\text { F:ATTCGCTCTCTTGGTATGACTGT } \\
\text { R:CCCAATTTGAAGTGTTGCTTTAC }\end{array}$ & $(\mathrm{TA})_{6}$ & 5 & $170-184$ & 0.054 & 0.045 & $0.380 \mathrm{n} . \mathrm{s}$ & 0.664 & $\operatorname{Pr} 032805690$ \\
\hline $\mathrm{BC} 4$ & $\begin{array}{l}\text { F:TATCAGCGTGTGTGAATAGTTGC } \\
\text { R:TAACCTAAATTCGAATCCATCCA }\end{array}$ & $(\mathrm{TA})_{7}$ & 4 & $157-163$ & 0.097 & 0.045 & $0.004 * *$ & 0.491 & $\operatorname{Pr} 032805691$ \\
\hline BC5 & $\begin{array}{l}\text { F:CAAACTTGGCTTAATACCATTCG } \\
\text { R:CCATGATCATCTCTATTTCAGGC }\end{array}$ & $(\mathrm{TG})_{9}$ & 3 & $119-125$ & 0.079 & 0.083 & $0.713 \mathrm{n} . \mathrm{s}$ & 0.469 & $\operatorname{Pr} 032805692$ \\
\hline BC6 & $\begin{array}{l}\text { F:CCTTAAGGAGATGCATTGTGAAT } \\
\text { R:GTATGAAGGGCATCAACAATAGG }\end{array}$ & $(\mathrm{TC})_{9}$ & 3 & $159-169$ & 0.000 & 0.000 & - n.c. & 0.299 & $\operatorname{Pr} 032805693$ \\
\hline $\mathrm{BC} 7$ & $\begin{array}{l}\text { F:GCTGAAAGTTGGTGATTGCTAGT } \\
\text { R:AGTTATGTCTTCGCTTGCTTCAG }\end{array}$ & $(\mathrm{AT})_{9}$ & 4 & $166-178$ & 0.120 & 0.125 & $0.087 \mathrm{n} . \mathrm{s}$ & 0.526 & Pr032805694 \\
\hline $\mathrm{BC} 8$ & $\begin{array}{l}\text { F:AACGTGAGAGTGCTAGTTCGGTA } \\
\text { R:TCTTCCTCACTTTATCATCCACG }\end{array}$ & $(\mathrm{TGA})_{5}$ & 3 & $167-173$ & 0.014 & 0.000 & $0.041^{*}$ & 0.17 & $\operatorname{Pr} 032805695$ \\
\hline BC9 & $\begin{array}{l}\text { F:AGAAGAGGTACGACAGTTTGCTG } \\
\text { R:TTCACGTCCGAATTCTTAGTCTC }\end{array}$ & $(\mathrm{GCG})_{5}$ & 2 & $156-159$ & 0.059 & 0.064 & $1.000 \mathrm{n} . \mathrm{s}$ & 0.195 & $\operatorname{Pr} 032805696$ \\
\hline $\mathrm{BC} 10$ & $\begin{array}{l}\text { F:CACTGCACATAGAAGGAGGAGTT } \\
\text { R:GTAATCGCCTACATGATTCATCC }\end{array}$ & $(\mathrm{GCG})_{6}$ & 5 & $108-129$ & 0.081 & 0.076 & $0.146 \mathrm{n} . \mathrm{s}$ & 0.581 & Pr032805681 \\
\hline BC11 & $\begin{array}{l}\text { F:CAGCAGTATGTCGGGATTATTTC } \\
\text { R:CCTCTGGTCATATTGCTGTTACC }\end{array}$ & $(\text { TTTCT })_{4}$ & 2 & $123-133$ & 0.000 & 0.000 & -n.c. & 0.155 & $\operatorname{Pr} 032805682$ \\
\hline $\mathrm{BC} 12$ & $\begin{array}{l}\text { F:AACAAGAGGGTCAGCTACAACAG } \\
\text { R:CAGCAATGGTATTAGCAGAGGAC }\end{array}$ & $(\mathrm{CAGCAA})_{4}$ & 4 & $160-178$ & 0.104 & 0.095 & $0.184 \mathrm{n} . \mathrm{s}$ & 0.549 & $\operatorname{Pr} 032805683$ \\
\hline $\mathrm{BC} 13$ & $\begin{array}{l}\text { F:ACCTTGACGATCCTTCATCTTCT } \\
\text { R:TTATGTTCTCCATATCCGTCAGC }\end{array}$ & $(\mathrm{GGTGCG})_{4}$ & 6 & $132-174$ & 0.124 & 0.095 & $0.161 \mathrm{n} . \mathrm{s}$ & 0.701 & $\operatorname{Pr} 032805684$ \\
\hline $\mathrm{BC} 14$ & $\begin{array}{l}\text { F:GGCAGCAATATAGCTCAAATACG } \\
\text { R:ACCTGATCGTTCACAACTTCATC }\end{array}$ & $(\mathrm{GACAAG})_{4}$ & 4 & $170-188$ & 0.196 & 0.083 & $0.000^{* * *}$ & 0.516 & $\operatorname{Pr} 032805685$ \\
\hline $\mathrm{BC} 15$ & $\begin{array}{l}\text { F:TCTTATTCAACACAACAGCCTGA } \\
\text { R:GCTGCAGTTGATAATGAGAAGGA }\end{array}$ & $(\text { ATGATA })_{4}$ & 5 & $151-175$ & 0.157 & 0.140 & $0.228 \mathrm{n} . \mathrm{s}$ & 0.528 & $\operatorname{Pr} 032805686$ \\
\hline $\mathrm{BC} 16$ & $\begin{array}{l}\text { F:ACCAATGGTCTATATTTCAACGG } \\
\text { R:TGTGCCCCACATAGCTTCTATCTA }\end{array}$ & $(\mathrm{ATTACT})_{4}$ & 6 & $149-179$ & 0.132 & 0.125 & $0.174 \mathrm{n} . \mathrm{s}$ & 0.643 & Pr032805687 \\
\hline $\mathrm{BC} 17$ & $\begin{array}{l}\text { F:TGACGAGGCTTCTACAGAATGAG } \\
\text { R:ACAAACAACAAGATGGGAATCAT }\end{array}$ & $(\mathrm{CATCCT})_{4}$ & 2 & $137-143$ & 0.034 & 0.045 & $1.000 \mathrm{n} . \mathrm{s}$ & 0.186 & $\operatorname{Pr} 032805688$ \\
\hline
\end{tabular}

674 Note: $N_{\mathrm{A}}=$ number of alleles per locus across all populations; $H_{\mathrm{E}}=$ expected heterozygosity

675 (mean value); $H_{\mathrm{O}}=$ observed heterozygosity (mean value); PIC, polymorphic information

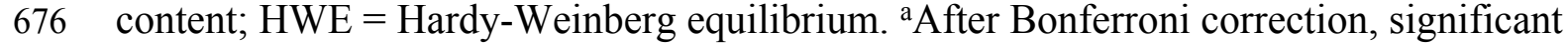

677 departures from Hardy-Weinberg equilibrium are indicated by $* P<0.05, * * P<0.01$, *** 
$678 P<0.001$. n.s. $=$ not significant; n.c. $=$ not calculated $($ Clarke $\&$ Gorley, 2001$)$. 
679 Table 3 GO, COG and KEGG annotation of 17 SSR-containing ESTs.

\section{Annotation}

\begin{tabular}{|c|c|c|c|c|c|}
\hline \multirow[t]{2}{*}{ Unigene $^{*}$} & \multicolumn{3}{|c|}{$\mathbf{G O}^{* *}$} & \multirow{2}{*}{ COG } & \multirow{2}{*}{ KEGG } \\
\hline & b. p. & c. c. & m. f. & & \\
\hline $\mathrm{BC} 1$ & - & 6 & - & function unknown & - \\
\hline $\mathrm{BC} 2$ & 1 & - & - & - & plant hormone signal transduction \\
\hline $\mathrm{BC} 3$ & - & - & - & - & - \\
\hline $\mathrm{BC} 4$ & 7 & - & 3 & $\begin{array}{l}\text { general function prediction only } \\
\text { signal transduction mechanisms } \\
\text { transcription } \\
\text { replication,recombination, and repair }\end{array}$ & $\begin{array}{l}\text { plant hormone signal transduction } \\
\text { plant-pathogen interaction }\end{array}$ \\
\hline $\mathrm{BC} 5$ & - & - & - & - & - \\
\hline BC6 & - & - & - & general function prediction only & - \\
\hline $\mathrm{BC} 7$ & 2 & 2 & - & general function prediction only & $\begin{array}{l}\text { biosynthesis of secondary metabolites } \\
\text { amino sugar and nucleotide sugar metabolism }\end{array}$ \\
\hline $\mathrm{BC} 8$ & 12 & 4 & 4 & $\begin{array}{l}\text { general function prediction only } \\
\text { signal transduction mechanisms } \\
\text { transcription } \\
\text { replication, recombination and repair }\end{array}$ & - \\
\hline BC9 & - & - & 2 & secondary metabolites biosynthesis, transport and catabolism & $\begin{array}{l}\text { biosynthesis of secondary metabolites } \\
\text { flavonoid biosynthesis } \\
\text { flavone and flavonol biosynthesis } \\
\text { sesquiterpenoid and triterpenoid biosynthesis } \\
\text { isoflavonoid biosynthesis }\end{array}$ \\
\hline $\mathrm{BC} 10$ & 2 & 4 & 1 & cell cycle control, cell division, chromosome partitioning & $\begin{array}{l}\text { metabolic pathways } \\
\text { endocytosis } \\
\text { ether lipid metabolism }\end{array}$ \\
\hline BC11 & - & - & - & - & - \\
\hline $\mathrm{BC} 12$ & 10 & 3 & 2 & $\begin{array}{l}\text { general function prediction only } \\
\text { posttranslational modification, protein turnover, chaperones }\end{array}$ & plant hormone signal transduction \\
\hline $\mathrm{BC} 13$ & - & - & - & transcription & - \\
\hline BC14 & - & - & - & - & - \\
\hline $\mathrm{BC} 15$ & 9 & 5 & 2 & - & - \\
\hline BC16 & - & - & - & - & - \\
\hline BC17 & - & - & - & - & - \\
\hline
\end{tabular}

680 Note: b. p.= biological_process; c. c.=cellular_component; m. f.= molecular_function. ${ }^{*}$ The 681 name of each unigene is replaced with the name of the EST-SSR maker it contains. ${ }^{* *}$ This table 682 shows only the number of the GO terms in the ontology for unigenes. The details of the GO 683 classification in three ontologies are shown in Supplemental Table S1. 
685

686 Figures

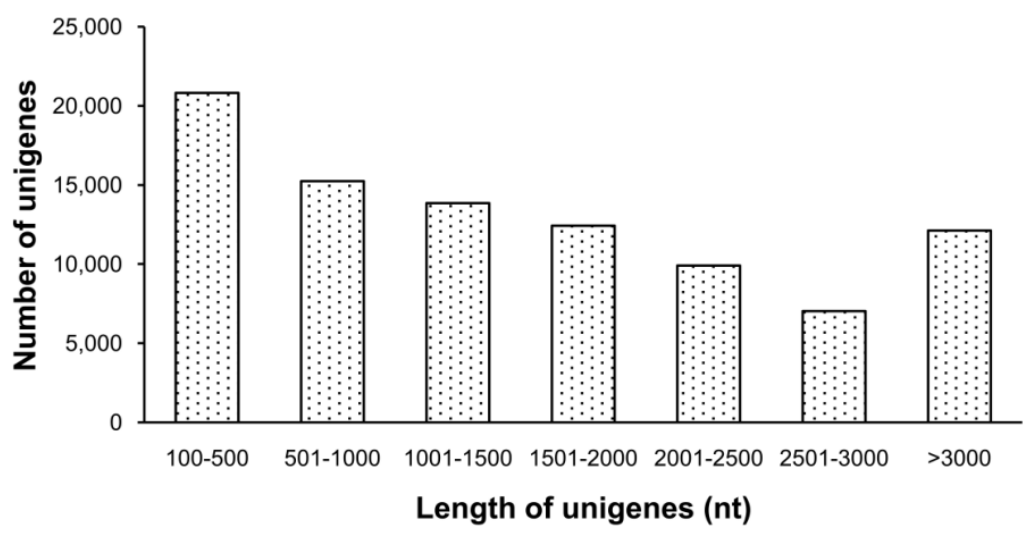

687

688 Figure 1 The length distribution of unigenes.

689 
690

691

692

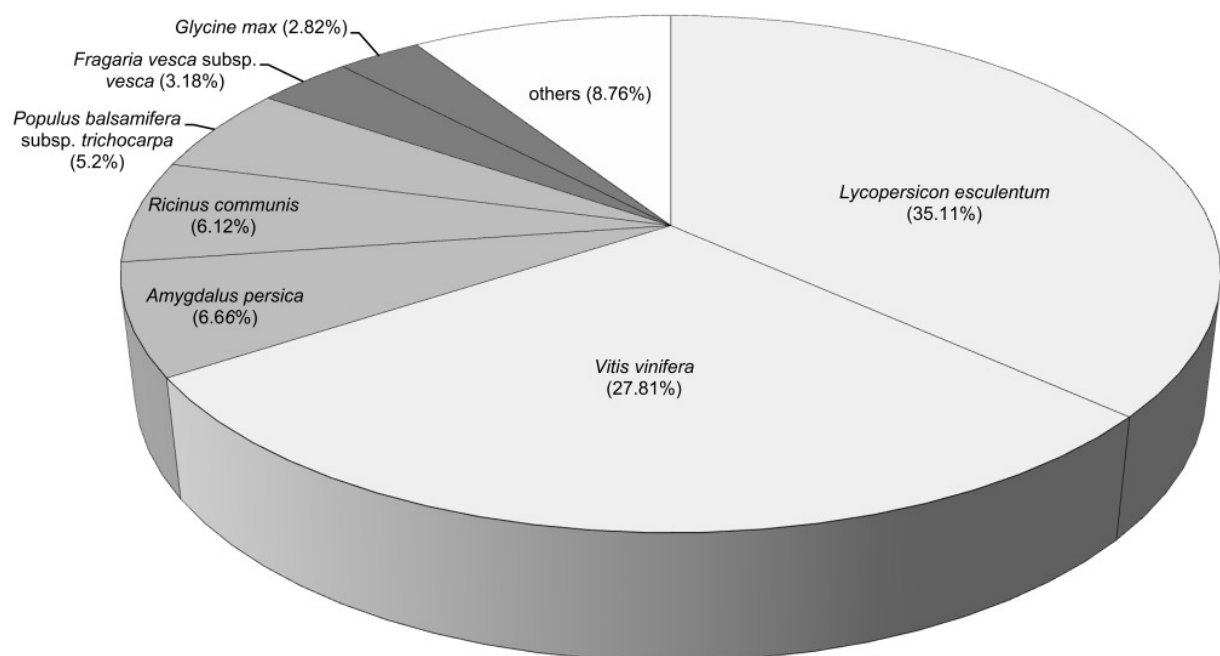

693 Figure 2 The species distribution of $\mathrm{Nr}$ annotations. 
694

695

696

697

698

699

700

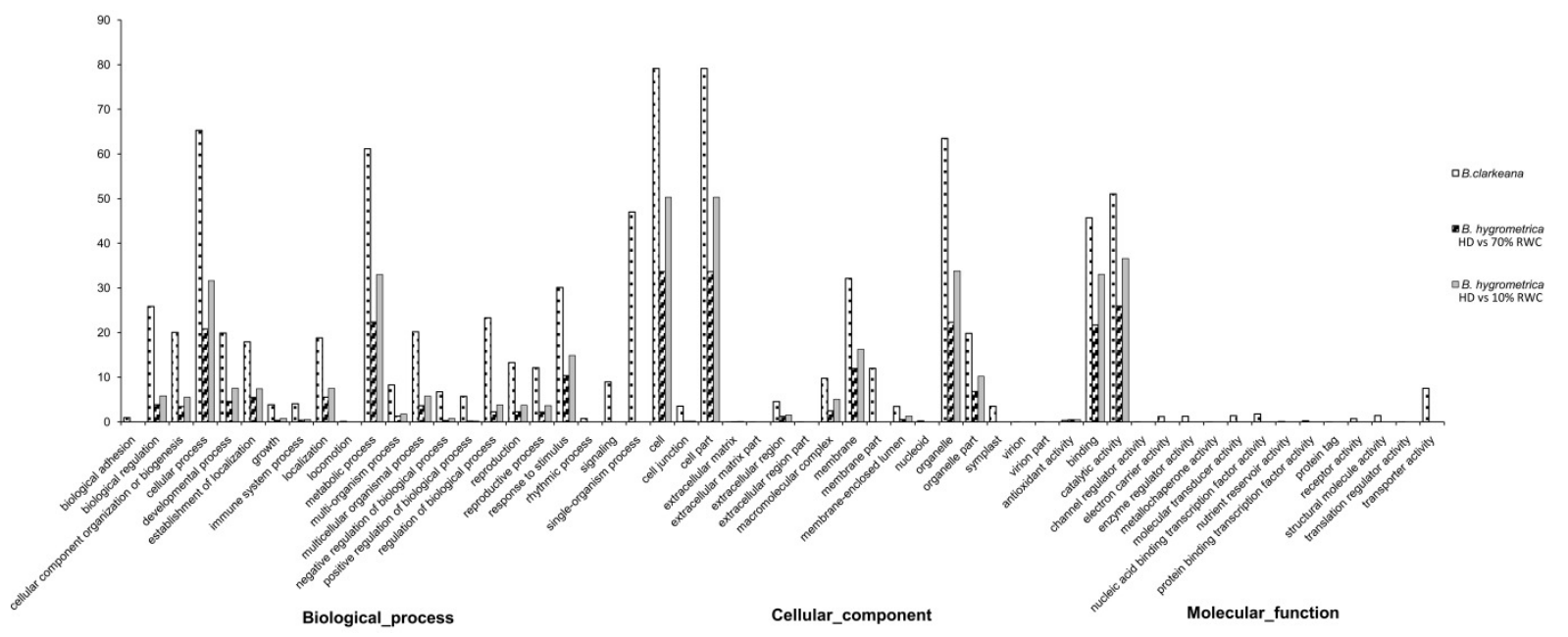

Figure 3 Gene ontology classification of unigenes between B. hygrometrica and B. clarkeana.

GO functions are shown in the $\mathrm{X}$-axis. The $\mathrm{Y}$-axis shows the percentage of genes annotated with the $\mathrm{GO}$ function. $\mathrm{RWC}=$ relative water content; $\mathrm{HD}=$ hydrated. 
701

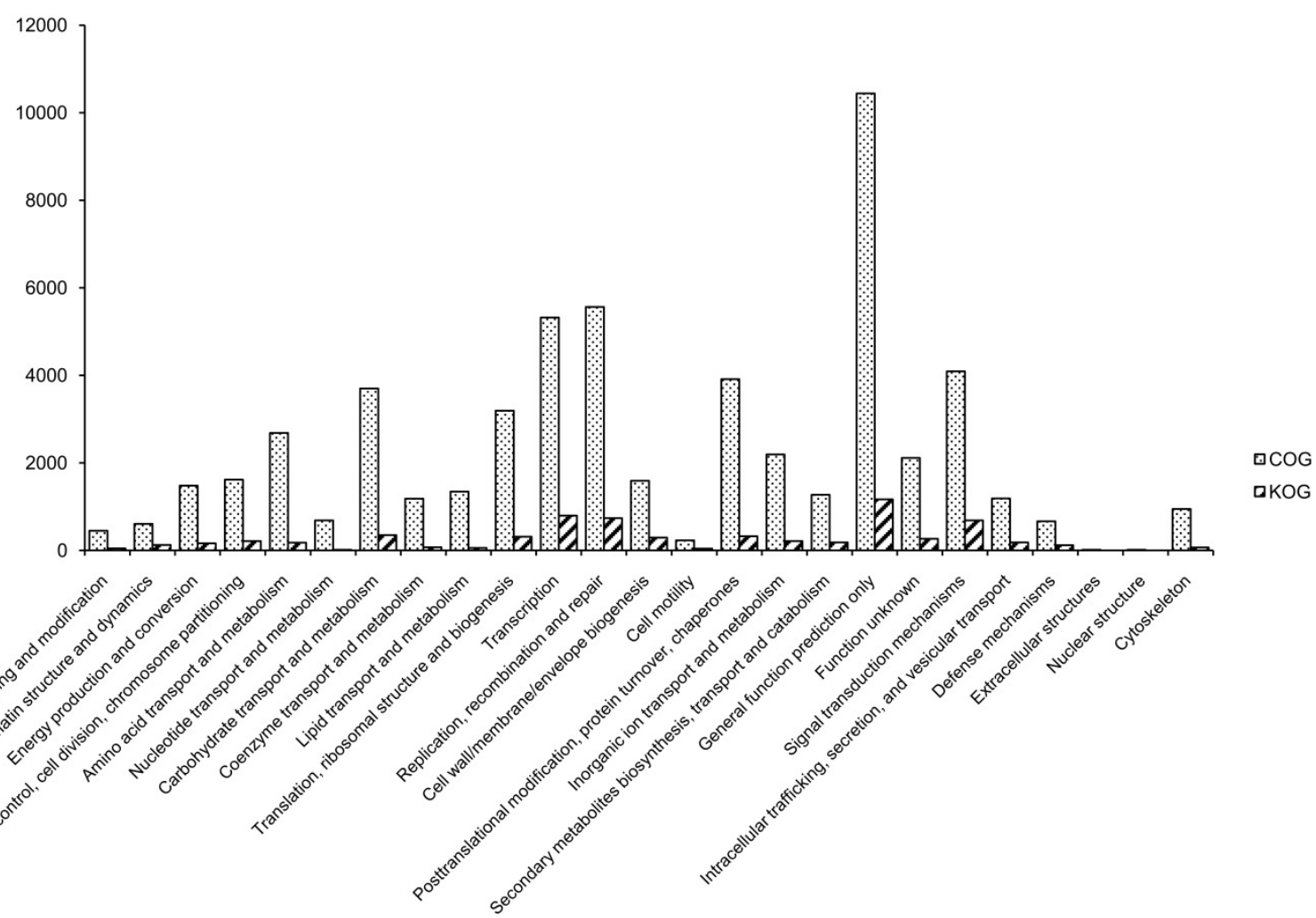

704 The horizontal coordinates are functional classes of COG and KOG, and the vertical coordinates 705 are numbers of unigenes in one class. 
706

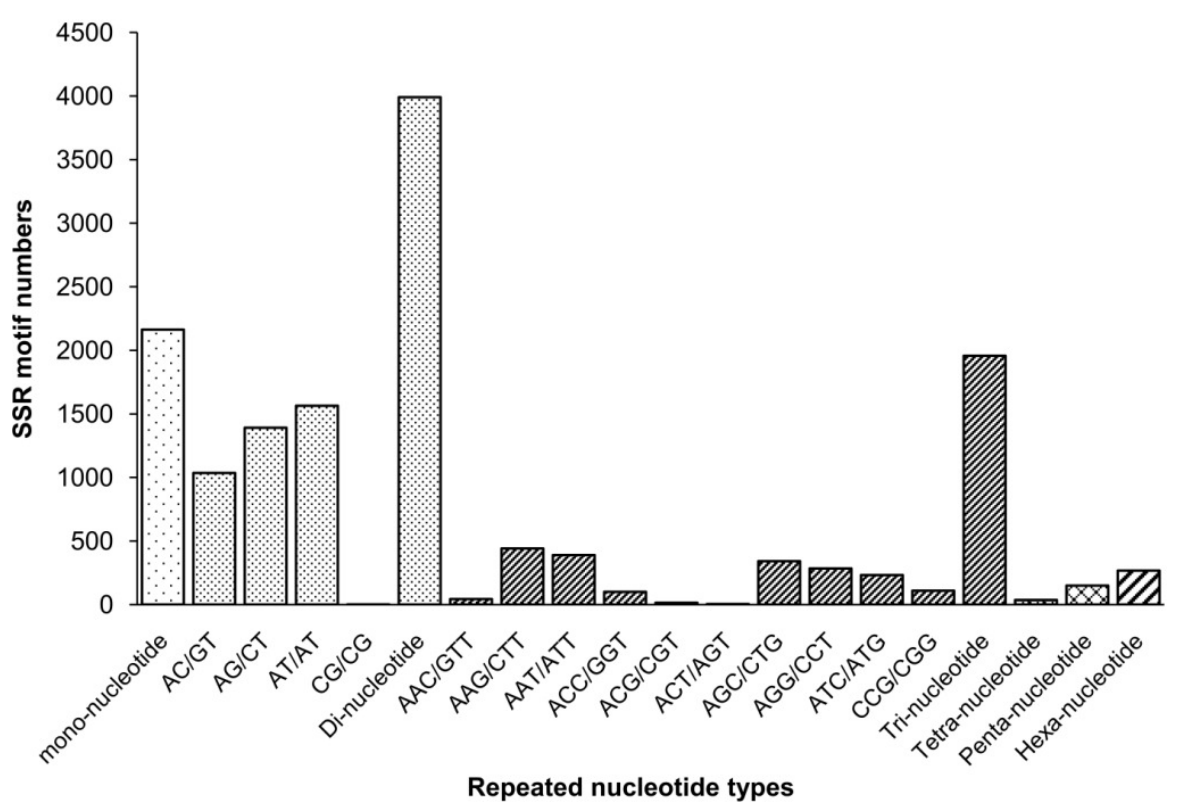

708 Figure 5 The distribution of the most repeated nucleotide types. 
709

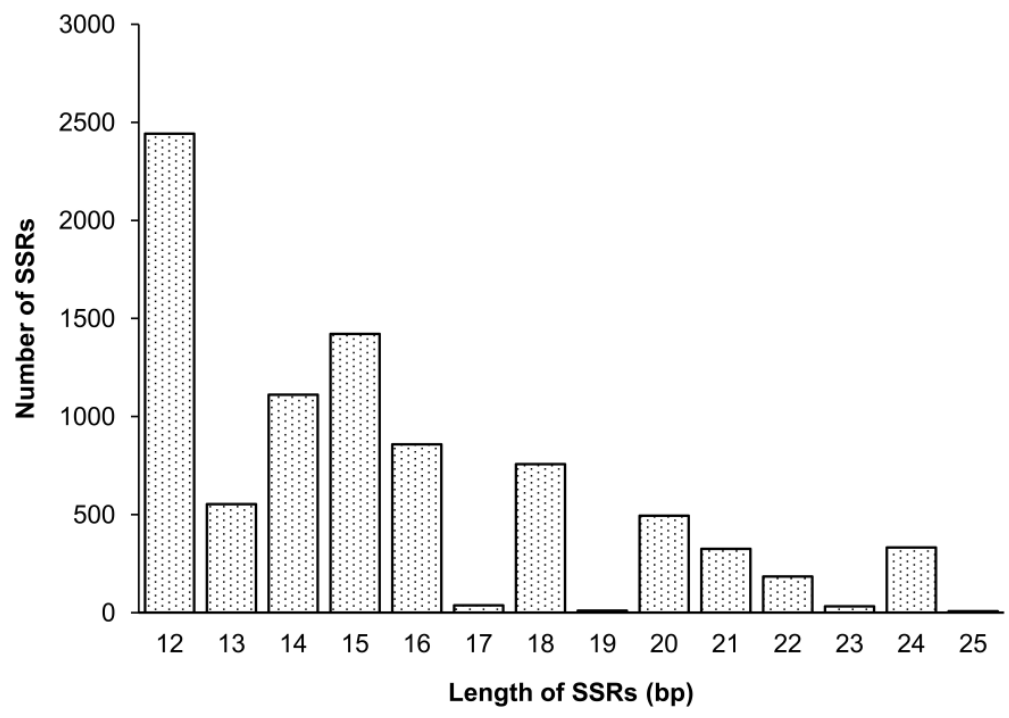

710

711 Figure 6 The distribution of SSRs of different lengths.

712 


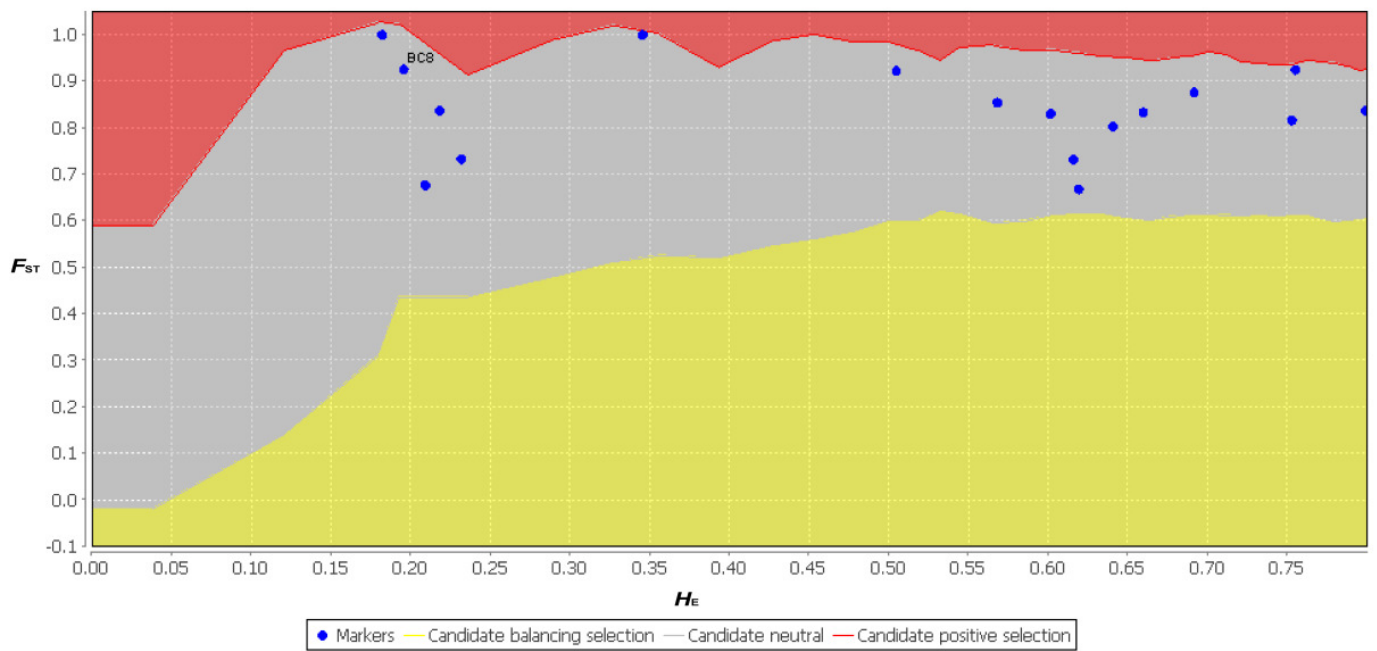

713

714

Figure 7 The neutral test results for 17 primer pairs using $F_{\mathrm{ST}}$ and $H_{E}$ from 11 populations

715 using LOSITAN.

716 